\title{
O transgênero e o direito previdenciário: omissão legislativa e insegurança jurídica no acesso aos benefícios
}

\author{
The transgender and the social security law: legislative omission \\ and legal insecurity on access to benefits
}

\author{
Dirceu Pereira Siqueira ${ }^{1}$ \\ Danilo Henrique Nunes ${ }^{2}$
}

\section{RESUMO}

A discussão sobre os indivíduos transgêneros tem sido mundialmente objeto de pauta tanto na seara social quanto na jurídica. Em relação a seus direitos e deveres são observadas a falta de legislação específica e a insegurança jurídica, não obstante, a Legislação Pátria assegura o atendimento ao princípio da isonomia e à dignidade da pessoa humana, bem como a obediência aos direitos fundamentais do indivíduo. O presente estudo concentra-se na abordagem acerca de tais elementos, com ênfase nos direitos previdenciários dos indivíduos transexuais, por meio do levantamento dos principais entendimentos acerca do tema, tanto em âmbito nacional quanto internacional, o que demonstra a necessidade de criação de novos mecanismos que projetem avanços nos direitos dos transgêneros.

Palavras-chave: Transexuais; Direito Previdenciário; Segurança Jurídica.

\section{ABSTRACT}

\footnotetext{
${ }^{1}$ Coordenador e Professor Permanente do Programa de Pós Graduação Stricto Sensu (Mestrado) em Direito no Centro Universitário de Maringá - PR (UniCesumar); Pós-doutor em Democracia e Direitos Humanos pelo Ius Gentium Conimbrigae da Faculdade de Direito da Universidade de Coimbra e pelo Centro de Estudos Interdisciplinares do Séc. XX da Universidade de Coimbra.

${ }^{2}$ Graduado em Direito pelo Centro Universitário da Fundação Educacional de Barretos (2012) e em Jornalismo pela União das Faculdades dos Grandes Lagos (2007). É Advogado militante nas áreas de Direito Constitucional, Tributário e Administrativo (de modo especial, licitações) com especialização em Direito Processual Civil e Didática para Ensino Superior pelo Centro Universitário da Fundação Educacional de Barretos e em Direito Constitucional pela Faculdade de Direito Damásio de Jesus. Aluno bolsista da CAPES no programa de Mestrado em Direitos Coletivos e Cidadania da Universidade de Ribeirão Preto - área de concentração: Direitos Coletivos e Cidadania, na linha de pesquisa - Concreção dos Direitos Coletivos e Cidadania. Curso com Nota 4 em avaliação da CAPES. Professor universitário e de cursos preparatórios para Exame Nacional da Ordem dos Advogados do Brasil e emcursos preparatórios para concursos públicos.
} 
The discussion on transgender individuals has been the subject of debate both globally and socially. In relation to their rights and duties are observed the lack of specific legislation and legal insecurity, nevertheless, the Homeland Legislation ensures compliance with the principle of isonomy and dignity of the human person, as well as obedience to the fundamental rights of the individual. The present study focuses on the approach to such elements, with emphasis on the social security rights of transgender individuals, by surveying the main understandings on the subject, both nationally and internationally, which demonstrates the need to create new mechanisms to advance advances in transgender rights.

Keywords: Transsexuals; Social Security Law; Legal Security.

\section{INTRODUÇÃO}

$\mathrm{O}$ atual momento social vivido pelo Brasil traz à tona debates acerca do sistema previdenciário brasileiro, sobretudo tratando-se das possibilidades e perspectivas da aplicabilidade de benefícios previdenciários para os indivíduos transgêneros - tema de discussão desse trabalho.

O conjunto de ações integradas relativas à Seguridade Social é assumidamente um importante mecanismo na proteção social dos indivíduos e uma das principais conquistas alcançadas com o advento da Constituição da República Federativa do Brasil de 1988. Este conjunto de ações que envolve Estado (poderes públicos) e a própria sociedade tem por fim assegurar determinados direitos no tocante à saúde, previdência e assistência social.

O Brasil, enquanto Estado Democrático de Direito, embasado por mecanismos e preceitos constitucionais, como a igualdade, a dignidade da pessoa humana e os direitos fundamentais, deve combater toda forma de discriminação. Nesse sentido, o debate envolvendo os benefícios previdenciários para os transexuais (sobretudo tratando-se da idade mínima para a aposentadoria, diferente para homens e mulheres) assume grande importância nos debates jurídicos e sociais, tanto no âmbito nacional quanto internacional.

O presente artigo inicia uma abordagem sobre preceitos constitucionais fundamentais de nosso ordenamento jurídico como a dignidade da pessoa humana e os direitos fundamentais, contextualizando-os sobre a ótica do Direito Previdenciário e seus benefícios, com enfoque nos direitos e deveres dos transexuais.

Também se analisa a omissão do legislador quanto a tais aspectos previdenciários e a insegurança jurídica causada a estes indivíduos. Para tanto é indispensável refletir que hoje já 
existem decisões judiciais resguardando alguns direitos dos transexuais, sobretudo o nome social e mudança de gênero em documentos, porém é necessário avançar nos aspectos previdenciários.

Por fim, este estudo também faz uma breve discussão acerca das perspectivas e prerrogativas envolvendo os benefícios previdenciários no âmbito internacional, com o objetivo de diagnosticar a situação do Brasil nesse aspecto, apresentando possibilidades de avanços no status quo do panorama nacional tanto pela via judicial quanto legislativa.

\section{DIGNIDADE DA PESSOA HUMANA E OS DIREITOS FUNDAMENTAIS: UMA ABORDAGEM INDISPENSÁVEL PARA ANALISAR O TRANSGÊNERO NA ÓTICA DO DIREITO PREVIDENCIÁRIO}

Destarte, para que seja possível contemplar o transgênero na perspectiva da omissão legislativa e da insegurança jurídica no acesso aos benefícios no âmbito previdenciário, cumpre-se a realização de uma apresentação concisa acerca dos Direitos Fundamentais e da relação de tais direitos com o princípio da dignidade de pessoa no Diploma Constitucional de 1988.

A Constituição da República Federativa de 1988 é composta por uma conjuntura de regras, normas, princípios e leis que estabelecem o Brasil enquanto um Estado Democrático de Direito. Trata-se do mais importante instrumento jurídico interno, visto que a Carta Magna norteia e concede diretrizes que organizam o funcionamento e estabelecimento de todo o ordenamento jurídico brasileiro.

A lei máxima brasileira foi estabelecida colocando o Estado como um ente soberano, mas condicionado a serviço da pessoa humana provendo, assim, os direitos e deveres dos cidadãos e do próprio Estado, coibindo que qualquer outra legislação no país conflite com ela ou seus princípios e fundamentos.

A dignidade da pessoa humana, além de um valor social, é um princípio jurídico fundamental estabelecido pelo Constituinte de 1988, bem como se relaciona intrinsecamente aos direitos fundamentais, sendo tal relação em maior ou menor nível.

Segundo Bernardo (2006) o princípio da dignidade humana advém historicamente da possibilidade de um indivíduo em contrair direitos e obrigações. Tal princípio é concedido a todos os indivíduos humanos na atualidade, o que nem sempre fora um retrato da realidade: 
$\mathrm{Na}$ época da escravatura, por exemplo, não era conferido tal direito ao escravo, visto que ao invés de ser concebido como um "ser" era concebido como um "ter", ou seja, propriedade de outro indivíduo, este sim detentor da posse de seus escravos e beneficiário da dignidade da pessoa humana.

No mesmo sentido, Dworkin (2002) aborda o princípio da dignidade da pessoa humana como um dos mais importantes princípios que norteiam o direito moderno. $\mathrm{O}$ autor fundamenta que um indivíduo jamais deve ser separado de sua dignidade e cumpre ao Direito assegurar a dignidade dos seres humanos como um preceito fundamental para que os mesmos possam viver uma vida justa e, por conseguinte, digna.

Observa-se neste paralelo que o sentido do princípio da dignidade da pessoa humana evolui com o tempo, antes apenas como a possibilidade do indivíduo adquirir direitos e contrair obrigações, inclusive tal garantia segregada a algumas castas mais abastadas e, hoje, tida como um direito universal, norteador de todo o direito moderno, sendo indissociável de qualquer ser humano.

Um importante marco histórico para a consolidação do princípio da dignidade da pessoa humana em âmbito nacional deu-se com o advento da Carga Magna de 1988. Nesse sentido:

\footnotetext{
(...) percebe-se que o Constituinte de 1988 plasmou, à guisa de fundamento da República Federativa do Brasil como Estado Democrático de Direito, a dignidade da pessoa humana, retratando o reconhecimento de que o indivíduo há de constituir o objetivo primacial da ordem jurídica. Dito fundamental36, o princípio - cuja função de diretriz hermenêutica lhe é irrecusável - traduz a repulsa constitucional às práticas, imputáveis aos poderes públicos ou aos particulares, que visem a expor o ser humano, enquanto tal, em posição de desigualdade perante os demais, a desconsiderá-lo como pessoa, reduzindo-o à condição de coisa, ou ainda a privá-lo dos meios necessários à sua manutenção (JUNIOR, 2000, p. 195).
}

Para Canotilho (2009) a dignidade da pessoa humana deve ser concebida como uma conjuntura na qual são contemplados os valores existentes na sociedade levando em consideração que a evolução e o desenvolvimento da sociedade passam a alterar seus valores, devendo o princípio da dignidade da pessoa, assim como o Direito, acompanhar tais mudanças adaptando-se as mesmas.

Portanto, como destacado, tem-se que cada sociedade, em cada época, elege aqueles direitos que lhes são mais prementes aos seus indivíduos, não sendo estes direitos estáticos, mas sim dinâmicos, tais como a própria sociedade. 
Canotilho (2009) complementa ressaltando que o princípio da dignidade da pessoa humana é preceito fundamental que exige aos seres humanos respeito por parte do Estado e da sociedade e elenca um rol de direitos e deveres que asseguram a proteção do ser humano contra atos considerados degradantes ou desumanos, que promovem o exercício da cidadania e o bem-estar da própria existência, a fim de nortear todo o viver dentro da sociedade.

Para Ridola (2014) a dignidade da pessoa humana é um valor que deve acompanhar a consciência e o constante sentimento de bem-estar de todos e cabe ao Estado assegurar que seus administrados usufruam de direitos indispensáveis para a manutenção de uma vida com dignidade, sendo um tópico amplamente indissociável do estudo acerca dos Direitos Fundamentais.

Deste modo, como aponta o autor, o Estado passa a ter uma postura ativa, não simplesmente passiva diante da garantia de tais direitos, pois não basta abster-se de ações que violem este direito, mas também há a necessidade de ações voltadas à garantia deles assegurando, assim, o que o autor chama de uma vida digna.

Nesse sentido:

O princípio da dignidade da pessoa humana foi estabelecido pela Constituição Brasileira como um princípio fundamental, norteador da República Federativa do Brasil (art. $1^{\circ}$, III, CF). A partir desta previsão constitucional, verifica-se que a dignidade humana deixou a esfera puramente axiológica para adentrar o âmbito normativo, assumindo o caráter de verdadeira norma constitucional, com funções primordialmente finalística e hermenêutica. A dimensão principiológica da dignidade da pessoa humana também foi objeto de estudo por Ana Paula de Barcellos65, que defende a dignidade da pessoa humana como verdadeira norma jurídica, dotada de imperatividade (OLSEN, 2006, p. 26).

A dignidade da pessoa humana, prevista no art. $1^{\circ}$, inc. III da Constituição Federal de 1988 é um dos fundamentos basilares do Estado Democrático de Direito. Esta se faz presente, também, no rol dos Direitos e Garantias Fundamentais, previsto no artigo $5^{\circ}$, o qual nos diz que "todos são iguais perante a lei, sem distinção de qualquer natureza, garantindo-se aos brasileiros e aos estrangeiros residentes no País a inviolabilidade do direito à vida, à liberdade, à igualdade, à segurança e à propriedade", sendo tratados em diversos incisos do artigo supramencionado (JUNIOR, 2000).

Segundo Piovesan (2004) a dignidade da pessoa humana é concebida como um dos princípios basilares do Diploma Constitucional de 1988, condicionando a interpretação das normas que integram o ordenamento jurídico brasileiro e incorporando-se junto aos Direitos e 
Garantias fundamentais, sendo o modelo ideal constitucional sob o qual o valor da dignidade da pessoa humana é incorporado ao ordenamento jurídico brasileiro.

Para a autora, o princípio da dignidade da pessoa humana é estabelecido justamente para assegurar a dignidade humana como um valor intrínseco às concepções modernas do Direito e da sociedade contemporânea.

Ridola (2014) destaca que é necessário atentar para a dimensão dupla (positiva e negativa) do princípio da dignidade da pessoa humana, sob a ótica jurídica:

A dimensão positiva insere a dignidade da pessoa humana como uma tarefa imposta ao Estado, para que este crie condições que permitam e fomentem a promoção do exercício da dignidade;

$>$ A dimensão negativa dispõe que ninguém sob qualquer hipótese pode atentar contra a dignidade de outrem, sendo sempre respeitada a autonomia.

Esse efeito dúplice apresentado pelo autor é necessário para a compreensão global do princípio da dignidade da pessoa humana especialmente nos aspectos práticos de sua atuação, seja entre os indivíduos ou entre eles e o Estado.

Ainda de acordo com o autor supramencionado a dignidade da pessoa humana é resultado da individualidade do ser humano, de sua razão e de sua consciência, sendo que o reconhecimento da proteção da dignidade da pessoa humana por parte do Estado (e, por conseguinte, do próprio Direito) é advindo da evolução do pensamento humano. O Direito, de tal forma, é concebido como um instrumento para assegurar a dignidade de cada ser humano, na medida de sua individualidade e especificidade.

Conforme apresentado, o estabelecimento da dignidade da pessoa humana como princípio basilar do Direito está inserido no artigo $1^{\circ}$, inciso III da Constituição Federal brasileira de 1988, sendo um dos fundamentos do Estado Democrático de Direito, constituído pela união indissolúvel dos Estados, Municípios e do Distrito Federal.

Para Junior (2000), o Diploma Constitucional é o instrumento adequado para assegurar o princípio da dignidade da pessoa humana como uma norma positiva, que norteia todos os demais instrumentos e mecanismos jurídicos que compõe o ordenamento jurídico brasileiro. Isso demonstra a importância da consolidação deste princípio tanto social quanto juridicamente para os indivíduos.

A despeito disso, ampliando esta visão, Prado (2007) leciona que o artigo $5^{\circ}$ da Carta Magna abarca os direitos e garantias fundamentais, os quais são considerados indispensáveis à 
pessoa humana, sendo fundamentais para assegurar uma existência baseada na dignidade, liberdade e igualdade. Assim, os direitos fundamentais previstos no Diploma Constitucional contemplam, entre outros fundamentos, a própria dignidade da pessoa humana.

Nesse sentido:

Os direitos fundamentais sociais presentes na Constituição de 1988 têm sua fundamentalidade garantida no texto constitucional positivo e na sua relação com valores e objetivos estampados na carta constitucional, especialmente com a dignidade da pessoa humana. São normas de caráter predominantemente principiológico, que estabelecem obrigações prima facie de prestar algo, de modo que sua aplicação geralmente requer ponderação com bens jurídicos ou direitos em sentido contrário, mediante análise da proporcionalidade. Ao demandarem do Estado prestações materiais, têm um inegável conteúdo econômico, que acaba por influenciar sua efetividade (OLSEN, 2006, p. V).

De tal modo, a dignidade da pessoa humana é um dos valores mais prestigiados pelo legislador ao estabelecer os direitos fundamentais na Carta Magna de 1988.

Canotilho (2009) ressalta que para que um direito seja considerado fundamental perante a Constituição deve haver a 'fundamentabilidade formal', que decorre da constitucionalização de direitos, contemplando que as normas de direito fundamental são hierarquicamente superiores em relação às demais normas do ordenamento jurídico, sendo submetidas em relação aos limites formais e materiais de revisão e emenda constitucional, sob os quais dispões o artigo 60 do Diploma Constitucional de 1988.

Neste sentido, observa-se com clareza que o artigo $60, \S 4^{\circ}$, inciso IV da CF/88 é taxativo ao disciplinar a vedação de propostas de emendas constitucionais tendentes a abolir os direitos e garantias individuais, o que demonstra a importância que o constituinte originário deu à matéria.

Conforme leciona Silva (2005) os direitos fundamentais previstos na CRFB/88 também podem ser denominados enquanto direitos fundamentais do homem, referindo-se a direitos essenciais para a sobrevivência e realização da pessoa humana na sociedade, positivados sob a égide do direito constitucional e vinculados aos seres humanos. Para o autor, não há como se falar nos direitos fundamentais sem considerar a dignidade da pessoa humana como um valor almejado por tais direitos.

Olsen (2006), no mesmo sentido, reafirma que o Constituinte de 1988 estabeleceu direitos positivados enquanto fundamentais relacionando-os a determinados valores, estabelecendo parâmetros materiais, exclusivos e excludentes como a dignidade da pessoa humana. Assim, a autora ressalta que o princípio da dignidade da pessoa humana não é apenas uma diretriz obrigatória para o poder público na esfera de autonomia do cidadão, mas também 
um direito positivo da pessoa humana, que assume relevância da identificação e fundamentação dos direitos fundamentais.

Para Sarlet (2005) o princípio da dignidade da pessoa humana é reconhecido como um critério indispensável para a identificação dos direitos fundamentais, os quais são considerados na medida de sua indispensabilidade tendo relação direta com o princípio da dignidade da pessoa humana. Para o autor, só podem ser considerados direitos fundamentais aqueles lapidados no princípio da dignidade da pessoa humana, criando-se direitos subjetivos.

Silva (2005), no mesmo sentido, destaca que o princípio jurídico fundamental da dignidade da pessoa humana constitui-se como a fonte jurídica e positiva dos direitos fundamentais, sendo tal princípio um valor que contempla todo o conjunto de direitos e garantias fundamentais. De tal modo, entende-se que o princípio da dignidade da pessoa humana detém inestimável valor jurídico no âmbito da produção dos direitos fundamentais.

Em contrapartida, Olsen (2006, p. 30) complementa que "vale ponderar que ainda que a dignidade da pessoa humana não possa ser tomada como único elemento material unificador e identificador dos direitos fundamentais - especialmente na Constituição Brasileira", de modo que o princípio da dignidade da pessoa humana é contemplado como um vínculo necessário, mas não autossuficiente, no estabelecimento dos direitos fundamentais na CRFB/88. De tal forma, os direitos fundamentais estão associados em maior ou menor nível ao princípio da dignidade da pessoa humana:

\begin{abstract}
Ao estabelecer como critério identificador dos direitos fundamentais aqueles decorrentes do regime e dos princípios que informam a Carta Constitucional, o constituinte fez referência, em verdade, a todos os princípios enumerados no Título I da Constituição Federal, dentre os quais o princípio democrático, o qual assume especial relevância para a identificação dos direitos fundamentais políticos. Mas é certo que o princípio da dignidade da pessoa humana tem um importante papel a cumprir, especialmente no caso dos direitos fundamentais sociais (OLSEN, 2006, p. 30-31).
\end{abstract}

Ora, vê-se que a dignidade da pessoa humana é um valor indispensável para que sejam estabelecidos os direitos fundamentais. Conforme se observa no Diploma Constitucional de 1988, o princípio da dignidade da pessoa humana, embora não expressamente citado no artigo $5^{\circ}, \S 2^{\circ}$ pelo Constituinte, como bem destaca Olsen, acaba norteando e embasando o estabelecimento dos direitos fundamentais.

Sarlet (2005) enfatiza que tanto a dignidade da pessoa humana quanto o estabelecimento de direitos fundamentais têm o objetivo de colocar o Estado brasileiro ao 
serviço dos cidadãos, visto que o Estado tão somente existe em função da pessoa humana, ainda na medida de sua soberania, e não o contrário. Para o autor, o princípio da dignidade da pessoa humana é aquele que contempla direitos que colocam os seres humanos em um patamar de igualdade entre si.

Diante de todo o exposto, pode-se afirmar que a dignidade da pessoa humana é tida como um dos valores e princípios social-jurídicos mais estimados no ordenamento jurídico brasileiro, visto que é considerado um critério indispensável na formação do Estado Democrático de Direito e também como o principal aspecto presente no embasamento jurídico do Constituinte de 1988.

Ainda que a dignidade da pessoa humana não seja apontada como um único elemento para identificar os direitos fundamentais, entende-se que tal vínculo é necessário, mas não autossuficiente, visto que no estabelecimento dos direitos fundamentais na Carta Magna de 1988 tais direitos estão associados em maior ou menor proporção ao princípio da dignidade da pessoa humana.

\section{O TRANSGÊNERO E O DIREITO PREVIDENCIÁRIO: ABORDAGEM GERAL E A OMISSÃO LEGISLATIVA EM ÂMBITO NACIONAL E INSEGURANÇA JURÍDICA}

De acordo com Quadrini e Venzzi (2016) embora o ordenamento jurídico brasileiro tenha evoluído de maneira significativa na possibilidade de reconhecimento de pessoas transexuais como detentoras de capacidade civil de acordo com o gênero sexual com o qual as mesmas são identificadas, tais avanços não são observados no âmbito dos benefícios previdenciários relativos ao tema.

Verifica-se que as prerrogativas desses indivíduos quanto aos direitos previdenciários são condizentes com os preceitos da dignidade da pessoa humana, dos direitos fundamentais e das disposições constitucionais referentes ao sistema de seguridade social e à previdência.

Barbosa (2014) contempla a importância da questão envolvendo os direitos dos transgêneros na atualidade, visto que se busca a igualdade de todos os cidadãos independentemente de suas características e especificidades. O autor destaca que no Brasil a retificação do nome civil e do sexo nos documentos pessoais é um processo complexo e bastante burocrático no qual as pessoas transexuais requerem tal mudança através da via 
judicial, o que, em tese, asseguraria os direitos previdenciários de tais indivíduos de acordo com o sexo transparecido em tais documentos.

Utiliza-se o termo "em tese", pois embora haja a mudança formal dos dados dos indivíduos transgêneros quanto aos aspectos documentais, o mesmo não ocorre para fins previdenciários, permanecendo o tratamento tal como antes da mudança, uma total dissonância com os aspectos materiais da situação.

De acordo com os ensinamentos de Alves (2013), os direitos dos transexuais são desenvolvidos a partir da realização da cirurgia de mudança de sexo, com possibilidade de pleitear o gênero sexual pelo qual tais pessoas se identificam. Tem-se que os direitos dos transexuais se equiparam aos direitos dos homossexuais indo além, por exemplo, com a possibilidade de consumar casamento ou de adotar filhos sem qualquer impedimento legal. No mesmo sentido, diante de uma condenação penal no qual há pena restritiva de liberdade, uma mulher transexual, por exemplo, deve ser encarcerada em um presídio feminino e não em um presídio masculino.

Os direitos dos transexuais, de tal modo, permitem que os mesmos detenham deveres e direitos de acordo com as perspectivas da aplicabilidade jurídica baseada na sua nova identidade de gênero e não na identidade de gênero com a qual nasceram tais indivíduos.

Entretanto, é nesse sentido que surge um dos maiores impasses envolvendo o novo contexto social e o Direito Previdenciário: A questão envolvendo o alcance e a concessão de benefícios previdenciários para tais indivíduos de acordo com a sua identidade de gênero obtida judicialmente.

Em seu estudo, Barbosa (2014) afirma que a exclusão dos direitos de indivíduos transgêneros vai contra o ideal do princípio da isonomia (todos são iguais perante a lei) e ao princípio da dignidade da pessoa humana. $\mathrm{O}$ autor fundamenta que não há como haver igualdade e justiça se os direitos relativos à previdência são negados pelo fato das condições físicas (ou seja, pelo fato da genitália com a qual nascera o indivíduo) serem mais estimadas do que o que fora estabelecido socialmente e juridicamente.

A crítica apresentada pelo autor quanto à exclusão dos direitos previdenciários dos indivíduos transgêneros é muito pertinente, haja vista o arcabouço constitucional de proteção dos direitos e garantias individuais, assim como a dignidade da pessoa humana, de modo que privilegiar aspectos físicos sobre todos os demais aspectos não parece ser o mais razoável. 
Já Fernandes (2010) buscou adequar em seu estudo os problemas práticos da omissão legislativa no tocante ao transgênero. $\mathrm{O}$ autor retrata o caso de mulher transexual (que havia modificado cirurgicamente seu sexo de masculino para o feminino) que tinha sido privada de inúmeros direitos no Reino Unido como, por exemplo, não tendo reconhecido seu direito de aposentar-se na idade mínima exigida para mulheres (no país, 60 anos). No caso em questão, a Corte Europeia de Direitos Humanos reconheceu tal violação e permitiu que qualquer transexual que houvesse se tornado mulher se aposentasse aos 60 anos no País.

Esta decisão paradigma demonstra a importância que o Poder Judiciário tem nestes casos, especialmente no tocante a resguardar direitos que o Poder Público deixa de reconhecer administrativamente a fim de evitar, com isso, enormes prejuízos aos administrados.

Nesse sentido:

É importante ressaltar que a alteração do sexo legal não é trivial para o sistema legal, que reconhece alguns direitos e obrigações diferenciadas para homens e mulheres, como a prestação de serviço militar obrigatório, tempo de aposentadoria, e outras relativas aos direitos de família, como maternidade e paternidade, filiação, casamento, que podem atingir direitos de terceiros (VENTURA; SCHRAMM: 2009, p. 83).

Conforme destacado pelos autores, as consequências da alteração do sexo legal não são triviais para o sistema legal, visto que devem ser analisados vários aspectos de direitos e obrigações que envolvem o caso. Diante disso, fica demonstrada a importância e relevância da discussão do tema.

Ora, ainda que haja um impasse acerca da questão envolvendo a aposentadoria de transgêneros, há uma tendência social e jurídica que viabiliza a aplicabilidade e possibilidade de que mulheres transexuais possam se aposentar de acordo com a idade mínima prevista para a aposentadoria das mulheres em caráter geral.

Os autores supramencionados fundamentam que uma vez que o Estado tutela o direito à mudança de sexo e o exercício de direitos e deveres de acordo com o sexo com o qual a pessoa transexual se identifica, tais direitos e deveres devem se estender ao âmbito previdenciário.

Lopes (2015) contemplou em seu estudo que, da mesma forma como ocorre com outros órgãos, na Previdência Social o transexual deve contrair e assumir todos os direitos e deveres de seu gênero. A autora, entretanto, aponta que há um descaso generalizado em tal âmbito citando o exemplo bastante comum nas forças armadas brasileiras: Quando um indivíduo atuante em tal organização se identifica como transexual, ele é aposentado 
compulsoriamente ou afastado. $\mathrm{O}$ que deveria ser inquestionável, entretanto, questiona-se: $\mathrm{O}$ indivíduo em questão contrai os benefícios previdenciários de acordo com o gênero com o qual o mesmo nascera ou com o gênero através do qual o mesmo se identifica?

Para Quadrini e Venzzi (2016) esse impasse jurídico em âmbito nacional é atribuído à omissão dos legisladores nesse sentido, constituindo-se uma verdadeira omissão legislativa que deve ser preenchida pela doutrina e pela jurisprudência, com pouco aporte legal. Nesse sentido tem-se que:

(...) resta ao Poder Judiciário preencher as lacunas existentes, para que os transexuais tenham acesso aos direitos garantidos pela Constituição, como qualquer outro cidadão. Destarte, utilizam-se como fundamentos à concessão da aposentadoria ao transexual mediante o preenchimento dos requisitos correspondentes ao gênero sexual a que este se adequou, o direito à vida, à integridade física, à saúde, bem como o princípio da igualdade e da dignidade humana (QUADRINI; VENZZI: 2016, p. 47).

Os autores destacam a importância do Poder Judiciário nesse sentido, pois através do poder integrador de suas ações, casos de injustiças administrativas, principalmente pelas omissões legais, podem ser revistos e retificados judicialmente. Eles ainda fundamentam que as atualizações legislativas com o objetivo de preencher lacunas e resolver omissões do Poder Legislativo devem estar amplamente relacionadas com os anseios sociais, sendo necessário assegurar o tratamento do transgênero perante toda a sociedade de acordo com o sexo por si identificado.

De acordo com Barbosa (2014) os benefícios previdenciários nesse sentido são compreendidos como as necessidades básicas de seguridade social previstas no sistema previdenciário brasileiro, como a idade mínima para aposentadoria, tradicionalmente de 65 anos para o homem e 60 para as mulheres. Rocha (2012) destaca que, de acordo com o artigo $7^{\circ}$, inciso XXX do Diploma Constitucional vigente e do artigo $1^{\circ}$ da Lei $n^{\circ} .9 .029 / 95$ não pode haver qualquer discriminação com o trabalhador submetido à cirurgia de designação sexual.

Assim, a omissão do legislador ao não dispor especificamente acerca dos benefícios previdenciários para os indivíduos que passaram pelo processo de mudança de sexo constituise como um grave problema jurídico da atualidade brasileira. Há ainda, uma grande insegurança jurídica para que tais indivíduos possam de fato usufruir de tais benefícios, conforme será apresentado a seguir.

Polezze (2015) leciona que a transexualidade é uma expressão da própria pessoa humana, devendo ser promovido o amplo respeito à identidade de gênero, de acordo com a percepção do próprio transexual. A ausência de leis no caso brasileiro é um exemplo da 
insegurança jurídica. Por este motivo as retificações nos registros civis ficam a cargo do Judiciário que, inclusive, acabam ficando com o encargo de definir temas de tamanha relevância social sem o aporte legal necessário:

\begin{abstract}
Por óbvio, a pendência de discussão judicial sobre assuntos tão importantes vem confirmar a insegurança jurídica que impera no tema. A esse respeito, o Superior Tribunal de Justiça, igualmente, tem manifestações sobre alteração de registro de transexual. As decisões da Quarta Turma78 e da Terceira Turma79 foram, de um lado, interessantes e bastante respeitosas aos interessados, pois deferiram as retificações de gênero e prenome nos registros civis, sem menção expressa nas respectivas certidões (resguardando, assim, a privacidade), mas é certo que não fugiram de uma visão mais tradicional, vinculando o gênero à genitália, uma vez que, em ambas as lides, os autores já haviam sido submetidos à cirurgia de redesignação sexual (POLEZZE, 2015, p. 294).
\end{abstract}

Ora, há insegurança jurídica envolvendo todos os aspectos dos indivíduos transgêneros. Os mesmos enfrentam grandes dificuldades para ter acesso aos benefícios como a retificação dos documentos, por exemplo, passando por extensos e demorados processos burocráticos. O mesmo se aplica aos benefícios previdenciários, constituindo-se tal desafio jurídico a partir da existência de tal lacuna legal e do clima de insegurança jurídica nesse sentido.

\title{
4. O TRANSGÊNERO E O DIREITO PREVIDENCIÁRIO: CONCEPÇÕES NO ÂMBITO INTERNACIONAL
}

As questões envolvendo os benefícios previdenciários e os transexuais são um tema de extrema relevância em todo mundo. O presente capítulo do artigo científico busca apresentar algumas concepções nesse sentido no âmbito internacional.

Fabeni e Agius (2009) apontam a necessidade de reflexão sobre os benefícios previdenciários para os transexuais. Segundo lecionam, para que haja segurança social e jurídica é imperioso tratá-los com igualdade, sendo indispensável estabelecer um esquema que ofereça proteção em todos os aspectos, não apenas no âmbito legal, mas também no próprio âmbito organizacional, de modo que as organizações devam assumir a responsabilidade em combater a discriminação aos transgêneros, de forma a possibilitar que o sistema de segurança social abranja esses indivíduos, com base no princípio da dignidade da pessoa humana e nas diretrizes constitucionais dos países. 
Assim, no entendimento dos autores, somente com ações concretas dos poderes públicos, assegurando os direitos dos transgêneros quanto aos benefícios previdenciários relativos ao gênero que se identifica, haveria o respeito aos princípios da igualdade e da dignidade da pessoa, bases das diretrizes constitucionais dos países.

De acordo com Farran (2013) a identificação da pessoa pelo seu sexo é uma questão indispensável, sobretudo tratando-se de direitos pensionais, previdência social, benefícios trabalhistas, entre outros. Assim, a categorização da pessoa de acordo com o sexo com o qual ela se identifica revela-se como uma das principais tendências do universo jurídico internacional neste aspecto. As Constituições da maioria dos estados das Ilhas do Pacífico asseguram a importância da categorização sexual, visto que o sexo determina grande parte do que a pessoa realizará durante a vida, bem como os diferentes direitos e obrigações contraídos pelos indivíduos.

Diante disso, o autor ressalta mais uma vez a importância da proteção à identificação pela pessoa de seu sexo, pois o sexo do indivíduo determinará uma série de obrigações e direitos que ele assumirá durante a vida, tais como os direitos pensionais, previdenciários, sociais, trabalhistas, entre outros, além das políticas públicas desenvolvidas para cada gênero.

De maneira geral, destaca-se que a palavra sexo vem do latim sexus e se refere tão somente à condição anatômico-fisiológica, ou seja, da distinção entre um macho e uma fêmea. Derivada do latim genus, a palavra gênero, entretanto, se refere ao código sob o qual se rege a organização social das relações advindas da concepção social entre os homens e as mulheres. Ora, enquanto o sexo possui caráter biológico e orgânico, o gênero trata do modo como as culturas interpretam e organizam as diferenças entre os homens e as mulheres.

Scott (1995, p. 76) afirma que "o uso do termo gênero enfatiza todo um sistema de relações que pode incluir o sexo, mas não é diretamente determinado pelo sexo, nem determina diretamente a sexualidade" (tradução livre realizada pelo autor do presente estudo, a partir do texto original, em inglês).

Assim o termo gênero é muito mais abrangente que o termo sexo, pois não abarca apenas aspectos fisiológicos, mas também comportamentais, psíquicos e sociais, de modo que sua determinação é muito mais complexa.

A necessidade de preencher lacunas legais acerca de tal tópico é trabalhada por Bergstedt (2008) em seu estudo. Para o autor, uma vez que há a mudança nos documentos de identificação, a mesma deve acompanhar os registros de seguridade social, de modo que os 
transgêneros passam a usufruir dos direitos e benefícios previdenciários segundo o gênero por eles escolhido.

Para Timmer e Senden (2015), uma vez que a pessoa se identifica com sexo diferente ao qual ela nasceu e tal identificação é tutelada pelo Estado, a mesma contrai direitos e obrigações do sexo com o qual ela se identifica. Qualquer ponto distinto disso, como a concessão de benefícios previdenciários de acordo com a genitália com qual a pessoa nascera, seria uma forma de discriminação, o que deve ser completamente repelido e combatido pelos legisladores modernos.

O entendimento dos autores citados acerca desta problemática dos transgêneros e suas possíveis soluções apresentadas são a vanguarda do direito atualmente na Europa, já que o tema por lá tem ganhado cada vez mais expressão.

Korkiamäki (2014) também compactua com o entendimento supramencionado, afirmando que uma vez que uma pessoa transexual passa a exercer seu direito de mudança de sexo, a mesma deve ser beneficiada pela lei sendo assegurada a segurança e eficácia jurídica para que tal pessoa usufrua de maneira contundente de todos os direitos e obrigações referentes ao sexo com o qual a mesma se identifica.

Portanto, a ideia de que os transgêneros devam ser respeitados na sua escolha do gênero é praticamente uníssona na Europa, sendo inclusive apontada pelos autores como condição para o respeito à dignidade da pessoa humana.

\section{CONSIDERAÇÕES FINAIS}

Diante do exposto, torna-se possível contemplar que há uma tendência no âmbito do direito nacional e internacional a assegurar maior segurança jurídica para os indivíduos transexuais com base no sexo com o qual tais indivíduos se identificam e não com o sexo com o qual tais indivíduos nasceram. O tópico em questão é considerado ainda bastante recente no sentido histórico, sendo fruto de intensos debates sob a orla social e jurídica.

Os indivíduos transexuais contam na atualidade com alguns mecanismos para assegurar que seus direitos sejam cumpridos, bem como seus deveres. Uma mulher transexual, por exemplo, em caso de condenação criminal, tem o direito de ser encarcerada em uma prisão feminina e não em uma prisão masculina, independentemente da genitália com a qual nascera. No mesmo sentido, entende-se que uma vez que estamos tratando dessa mesma mulher transexual do exemplo, a mesma deve contemplar os benefícios 
previdenciários incluindo a idade mínima para aposentadoria nos termos impostos pela legislação.

O Brasil caminha a passos lentos para que seja criada tal igualdade com base no princípio da dignidade da pessoa humana e nos direitos fundamentais dos indivíduos. A omissão do legislador em dispor sobre tal matéria e a insegurança jurídica presente no tópico refletem acerca da importância do Judiciário para dispor sobre as questões envolvendo os transgêneros e o Direito Previdenciário, bem como diagnostica uma necessidade de criação de novos mecanismos a fim de assegurar que os indivíduos transexuais sejam beneficiados nesse aspecto.

\section{REFERÊNCIAS BIBLIOGRÁFICAS}

ALVES, G.B. Transexualidade e direitos fundamentais. Trabalho de Conclusão de Curso (Graduação em Direito) - UEP. Campina Grande, 2013.

BARBOSA, Bruno Rafael Silva Nogueira. Construindo Uma Identidade dos Direitos Trans: Uma busca por uma Adequação do gênero aos seus Direitos Previdenciários. Conteudo Juridico, Brasilia-DF: 14 jun. 2014. Disponivel em: <http://www.conteudojuridico.com.br/?artigos\&ver=2.48601\&seo=1>. Acesso em: Jul/2017.

BERGSTEDT, A.S. Estate Planning And The Transgender Client. Western New England Law Review Volume 3030 (2007-2008) Issue 3 Symposium: Issues In Estate Planning For Same-Sex And Transgender Couples.

BERNARDO, W.O.L. O Princípio Da Dignidade Da Pessoa Humana E O Novo Direito Civil: Breves Reflexões. Revista da Faculdade de Direito de Campos, Ano VII, No 8 - Junho de 2006.

BRASIL. Constituição Federal de 1988. Promulgada em 5 de outubro de 1988. Disponível em <http://www.planalto.gov.br/ccivil_03/constituicao/constituição.htm> Acesso: Jul/2017.

CANOTILHO, J.J.G. Estudos sobre Direitos Fundamentais. São Paulo: RT, 2009.

DWORKIN, R. Levando os direitos a sério. São Paulo: Martins Fontes, 2002.

WOLF, Guilherme Eidelwein; BUFFON, Marciano. Custeio da seguridade social no Brasil: a controvérsia acerca do suposto déficit previdenciário. Revista Direitos Sociais e Políticas

Públicas - Unifafibe. V. 5, N. 1, 2017. 
FABENI, S; AGIUS, S. Transgender People And The Gender Recast Directive Implementation Guidelines. The European Region of the International Lesbian, Gay, Bisexual, Trans \& Intersex Association (ILGA). December 2009.

FARRAN, S. Transsexuals, Fa'afafine, Fakaleiti And Marriage Law In The Pacific: Considerations For The Future. 2013. Disponível em: www.jps.auckland.ac.nz/docs/Volume113/jps_v113_no2_2004/1\%20Transsexuals.pdf Acesso: Jul/2017.

FERNANDES, E.B.D. O TRANSEXUAL E A OMISSÃO DA LEI: UM ESTUDO DE CASOS PARADIGMÁTICOS. Caderno Virtual Nº 21, v. 1 - Jan-Jun/2010.

JUNIOR, E.P.N. O direito brasileiro e o princípio da dignidade da pessoa humana. Brasília a. 37 n. 145 jan./mar. 2000.

KORKIAMÄKI, I.S. Legal Gender Recognition and (Lack of) Equality in the European Court of Human Rights. The Equal Rights Review, Vol. Thirteen (2014).

LOPES, A.L.M.D. O Direito À Identidade De Gênero E Ao Nome Civil Dos Transexuais: Uma Análise Do Atual Cenário E Da Necessidade De Adequação Das Normas Brasileiras. Trabalho de Conclusão de Curso apresentado como requisito parcial para obtenção do grau de Bacharel em Ciências Jurídicas e Sociais pela PUC/RS. Porto Alegre, 2015.

OLSEN, A.C.L. A Eficácia Dos Direitos Fundamentais Sociais Frente À Reserva Do Possível. Dissertação apresentada no Curso de PósGraduação em Direito do Setor de Ciências Jurídicas da Universidade Federal do Paraná. Curitiba (2006). Disponível em: <http://dominiopublico.mec.gov.br/download/teste/arqs/cp007711.pdf> Acesso: Ju1/2017.

PIOVESAN, F. Direitos Humanos, O Princípio da dignidade da pessoa humana e a Constituição de 1988. 2004.

POLEZZE, R.V. Transexuais: a fragilidade do tratamento jurídico. Revista Juris Poiesis ano $18, \mathrm{n}^{\circ} 18$, jan-dez.2015 ISSN 1516-6635

PRADO, J.C.N.A. Direitos Fundamentais: Direito De Todos? O Dever Ético Constitucional E A Reserva Do Possível. Revista Brasileira de Direito Constitucional - RBDC n. 10 - jul./dez. 2007

QUADRINI, M.C.J; VENAZZI, K.F. O Direito Previdenciário Dos Transexuais: Percepção Dos Benefícios De Aposentadoria Por Tempo De Contribuição E Por Idade. ROMED Volume 2| Número 2 | Set. 2016.

RIDOLA, Paolo. A dignidade humana e o "princípio liberdade" na cultura constitucional europeia. Porto Alegre: Livraria do Advogado Editora, 2014. 
ROCHA, Marcel Fernandes de Oliveira. Transexualidade: cirurgia de adequação ao sexo e problemas jurídicos dela decorrentes. Revista de Filosofia do Direito, do Estado e da Soiedade, Natal, v. 3, n. 1, p.168-184, jan. 2012. Semestral. Disponível em: <http://www.revistafides.com/ojs/index.php/br/article/viewFile/270/513>. Acesso em: $\mathrm{Jul} / 2017$.

SARLET, Ingo Wolfgang. A Eficácia dos Direitos Fundamentais. 5 ed, rev. atual. amp. Porto Alegre: Livraria do Advogado, 2005.

SCOTT, J. Gender: a useful category of historical analyses. Gender and the politics of history. New York, Columbia University Press. 1989.

SILVA, José Afonso. Curso de Direito Constitucional Positivo. São Paulo: Malheiros, 2005, p. 178.

SIQUEIRA, Dirceu Pereira; CASTRO, Lorenna Roberta Barbosa. Minorias e grupos vulneráveis: a questão terminológica como fator preponderante para uma real inclusão social.

Revista Direitos Sociais e Políticas Públicas - Unifafibe. V. 5, N. 1, 2017.

TIMMER, A; SENDEN, L. A comparative analysis of gender equality law in Europe. European Comission, 2015.

VENTURA, M; SCHRAMM, F.R. Limites e possibilidades do exercício da autonomia nas práticas terapêuticas de modificação corporal e alteração da identidade sexual. Physis Revista de Saúde Coletiva, Rio de Janeiro, 19 [1]: 65-93, 2009. 